\title{
Information Heuristics of Information Literate People
}

\author{
Katarzyna Materska \\ Cardinal Stefan Wyszyński University in Warsaw \\ Warsaw, Poland \\ katarzyna.materska@gmail.com
}

\begin{abstract}
It is confirmed through information users' daily activities that they apply many shortcuts, ignore some information and use heuristics - particularly in electronic social networking environments. The critical analysis of the literature and research findings are used as a base to identify and create a short (preliminary) inventory of information heuristics that people use at various stages of seeking and conducting source evaluation (credibility assessment) to solve their everyday information problems. The use of heuristics (understood as sense-making activities that help information users to make a satisfying choice of the sources and distinguish the content of various quality and sufficiency) is discussed in the context of information literacy (IL) concept. The analysis of heuristics offers some additional explanation of online information behavior and personal information management strategies. The result of the research is a proposal to treat heuristics as intuitive but not accidental search tactics based on experience that should be included in IL training.
\end{abstract}

Keywords: Cognitive heuristics, information literacy, digital literacy, information credibility, information evaluation, bandwagon effect, information seeking behavior.

\section{Introduction}

While turning towards the electronic environment, people increasingly face a multitude and variety of information and sources to be found, evaluated, extracted, synthesized, interpreted, approved and used. Time deficit and insufficient skills make information users apply many shortcuts, ignore some information and use heuristics. The use of heuristics - understood as sense-making activities that help information users to make a satisfying choice of the sources and distinguish the content of various quality and sufficiency to reach appropriate decisions - seems to be very sensible in complicated information environments. It can be deliberate or intuitive at many stages of people's information activities - when they seek something on the Internet, use search engines, conduct source evaluation (credibility assessment) and critical reading.

What does it mean to be information literate in the contemporary world? Finding an answer to this question may be as difficult as defining the concept of IL. There are diverse scholarly traditions and approaches to the components of information (and, in a broader sense, multimedia) literacy. In her understanding of IL area the author is far 
- similarly to some other researchers [1-2] - from treating IL in terms of formal educational contexts of instruction, specialized institutions (libraries) and traditional roles often based on bibliographic information systems. The practice and experience of Internet users places IL within digital and networked daily activities (the workplace, too), often emphasizing social cooperation and context as IL tools.

In the author's opinion, the process of becoming information literate requires understanding numerous possible ways of interacting with information and new media and the awareness of the implications of such behavior. Thus, in this context, the knowledge of heuristics one (can) use(s) (deliberately or intuitively) is a component of an information literate individual in an information-intensive world.

\section{Objectives and Methodology}

As the topic of cognitive heuristics is nearly absent in the literature of library and information science [3], this paper begins with an attempt to identify and explain heuristics that people use at different stages of locating "the best" (i.e. good enough) online sources for solving their information problems and taking decisions. Critical analysis of the literature and research findings from several different areas (e.g. psychology, cognitive science, theories from information processing, credibility studies, human-computer interactions) are used as a basis to discover the most prominent heuristics and create a short (preliminary) inventory of information heuristics - in particular turning to credibility assessment. The size limitations of this paper do not allow the author to elaborate on the topic.

The important objective of this paper is to direct the attention of IL researchers and practitioners towards the problem of cognitive heuristics and encourage researchers to incorporate cognitive heuristics practice into the IL area. Heuristics provide a significant explanation of information users' behavior in online social networking information landscapes and create, in the context of information literacy (IL), new challenges to information literacy educators.

\section{Digital Information End User - Satisficer}

Each day people deal with a variety of sources to be found, read, evaluated, synthesized, interpreted, transferred and communicated to others. Consciously or not, they make decisions - what to find, when and how to do it, what sources and tools should be used, when to finish the search stage, what and when decides that something is recognized to be credible. People increasingly turn to online sources for information to guide their decisions. The media world of modern youth is almost completely digital. With the arrival of personal broadcasting technologies many youngsters experience the world through their own self-expression and the expressions of their peers. Customization in the digital age enables users to serve not merely as consumers of information but also as gatekeepers of content and the sources of communication via digital media such as blogs, social networking websites, music playlists, e-commerce websites. At the same time, they are forced to evaluate the vast 
amount of online information on their own and individually find information they can trust.

The unprecedented amount of information available for public consumption makes the origin of information, its quality, and veracity less clear and digital information more prone to be out-of-date, incomplete or inaccurate than before [4]. Each new technology extends and deepens information offered to end users, thereby complicating the process of information seeking and knowledge discovery, particularly on the Web. In the environment of information scarcity, traditional methods reduced the uncertainty about the credibility on the basis of personal knowledge or reliance on information intermediaries such as experts, professors, opinion leaders, reviewers, librarians and other information arbiters. Not so long ago the recommended approaches to online information evaluation typically included five criteria that users should employ: checking the accuracy, authority, objectivity, currency, and coverage/scope of the information and/or its source [5]. The contemporary media landscape looks quite different now than it did even just a short time ago. Internet users rarely engage in effortful information evaluation tasks, basing their decisions on the visual design elements of websites and their navigability, preferring peripheral cues to any content or source information. They do not spend much time at any given site so they develop quick strategies for assessing credibility (as one of the criteria for relevance judgment). Findings from credibility studies [6] and theories in information processing and cognitive science [7] share the notion that people do not always invest their full mental capacities in information evaluation tasks. According to the idea of bounded rationality [8], individuals' behavior is adaptive, which means that people seek an optimal balance between cognitive effort and desired outcomes. One form of bounded rationality is satisficing, when people do not use all their cognitive resources to obtain optimal outcomes, but instead use just enough (good enough) resources to provide a sufficiently optimal outcome for the given context. Satisficing may thus be a common strategy used by Internet information seekers. It is worth noting that the success of a search is not the same as the authority of its results [9].

\section{Homo Heuristicus}

Judgment under uncertainty leads to the use of simplifying heuristics. People use simple rules available in their judgmental contexts to assess the validity and quality of a message without fully absorbing its semantic content. According to Gigerenzer and Todd, heuristics "employ a minimum of time, knowledge, and computation to make adaptive choices" [10, p. 14].

Cognitive heuristics (mental shortcuts) are information processing strategies that enable users to ignore part of the information to make decisions more quickly, frugally, accurately and with less effort than with more complex methods, and thus they reduce the cognitive load during information processing [11]. Making judgments more accurately by ignoring information is a new concept. The discovery of the "lessis-more effect" contradicts the most popular model of human cognition in terms of accuracy-effort trade-offs. "Less-is-more" does not mean that the less information one 
uses, the better the performance is. Rather, it refers to the point at which more information or computation becomes detrimental, irrespectively of the costs. Referring to less information Gigerenzer and Brighton [12] refer to ignoring cues, weights, and dependencies among cues.

The fact that simple heuristics can be more accurate than complex procedures is one of the major discoveries of the last decades [13]. While in some approaches heuristics were thought to lead to biased or faulty information processing [14], modern research shows heuristics can serve an important function in helping people to cope effectively with the vast quantities of information they encounter every day, and frequently they result in accurate decisions [10].

The use of heuristics supports people's objective of finding information quickly and conveniently, without any substantial engagement with the information or source itself. Hilligoss and Rieh [6] revealed in their research four categories of heuristics: media- related (when people may perceive certain media or specific media formats to be more or less credible), source-related (well-known sources are more credible than the unfamiliar ones, primary sources are more credible than the secondary ones), endorsement-based (information sources and objects widely used are more likely to be credible), and aesthetics-based (if people invest a significant amount of time in the careful design of a website, they spend more time on what they want to say).

Heuristics achieve accuracy by means of a successful exploitation of evolved mental abilities and environmental structures. The classical critique of the models "more information is always better" assumes that, as in the real world the search for information costs time or money, there is a point at which the costs of further search become no longer justified. This has led to optimization-under-constraints theories in which the search in the world is terminated when the expected costs exceed the benefits [12, p. 110]. Gigerenzer and Brighton [12] in their concept of "homo heuristicus" suggested the human mind resembles an adaptive toolbox with various heuristics tailored for specific classes of problems. They presented ten well-studied heuristics for which there was evidence that they were included in the adaptive toolbox of humans.

In 2011 Gigerenzer and Gaissmaier [11] reviewed studies on decision making done by individuals and institutions, including business, medical (health care), and legal decision making, that show heuristics often to be more accurate than complex "rational" strategies. Their research indicates that $(a)$ individuals and organizations tend to rely on simple heuristics in an adaptive way, and $(b)$ ignoring part of the information may result in more accurate judgments than weighting and adding all information in some situations. This puts heuristics on a par with statistical methods and emphasizes a new ecological question: in what environment does a given strategy (heuristic or otherwise) succeed?

Although the study of heuristics has been typically considered as purely descriptive, less-is-more effects introduce a prescriptive role for heuristics, resulting in two research questions:

1. Description: which heuristics do people use in which situations?

2. Prescription: when should people rely on a given heuristic rather than a complex strategy to make more accurate judgments? [11, p. 453]. 
Sundar [4] was perhaps the first researcher who claimed that credibility evaluations performed online were guided by heuristic processes. He proposed the MAIN model to guide the examination of the credibility heuristics that stem from four technological features or "affordances" inherent to the Internet, including modality (i.e. whether information is presented as text, audio, or video), agency (i.e. users' perceived source of the information), interactivity (i.e. whether one can serve both as a source and a receiver of information), and navigability (i.e. the ease of locating relevant information). The MAIN model suggests several heuristics tied to each affordance that are likely to play some role in the credibility determination. Responding to Sundar's call for investigation of the heuristic processes of credibility evaluation, the researchers have begun to seek empirical evidence for heuristics used in credibility evaluation (e.g., [6], [15-16]).

\section{$5 \quad$ Digital Information User - Animal Sociale}

Blogs, wikis, social bookmarking, social networking sites, ratings, recommendations and other tools confirm the image of Internet use and users as a vigorously social one. Individuals do not make credibility judgments in isolation from one another, thereby ignoring social tools for credibility evaluation. On the contrary, they adopt new possibilities and realities of the Web environment, which offers new means for social- and group-based information evaluation and credibility assessment. In cyberspace the traditional notions of credibility as originating from a central authority (a teacher, expert, doctor or organization) are problematic now, and even outdated. In the Internet environment people must defer to the external sources of knowledge; they harness collective intelligence. "The result may be a shift from a model of single authority based on scarcity and hierarchy to a model of multiple distributed authorities based on information abundance and networks of peers" [15, p. 415].

Internet users genuinely care about the opinions of millions of other anonymous users. "If everyone agrees, then the message is probably true" says a bandwagon heuristic. The term "bandwagon" can be traced back to earlier studies on persuasion and propaganda, meaning to join the winning side or get associated with what is likely to be successful. The bandwagon effect therefore describes how the prevailing view of the community affects one's attitude and decisions motivated by the need for conformity. There is plenty of evidence in the literature to confirm that online users are driven by these cues. [16, p.2]. The bandwagon heuristic is of particular relevance today as it reveals the user-driven nature of the Internet.

In their study, Sundar et al. [17] explain the bandwagon heuristic using the example of Google News that automated the process of news selection. In order to help users cope with the resulting overload of information, news leads are typically accompanied by three cues: (1) the name of the primary source from which the headline and lead were borrowed, (2) the validity of posted stories - the time elapsed since the story broke, and (3) the number of related articles (NRA) written about this story by other news organizations tracked by the newsbot. The information scent transmitted by the NRA cue may trigger the bandwagon heuristic ("if so many news organizations think this is news, then it must be news"). 
Sundar et al. [17] have identified a variety of heuristics associated with interface cues in online persuasive communication that may contribute to attitude formation/change and purchase decisions. When facing large amount of information (especially in the e-commerce - in the context of online shopping), individuals may choose to reduce the cost of searching by relying on the interface cues and applying cognitive heuristics [15].

\section{Heuristics in the Evaluation of Credibility}

Networked digital media pose new challenges to people as regards locating information the latter can trust. The results of the Metzger, Flanagin and Medders' research clearly show that "a common strategy employed by Internet information seekers is to minimize cognitive effort and mitigate time pressures through the use of heuristics" [15, p. 434]. In their study of credibility assessment they reveal several cognitive heuristics employed by the participants in their research: reputation, endorsement, consistency, self confirmation, expectancy violation and persuasive intent. They illustrate the types of cognitive heuristics that information consumers employ when determining what sources and information to trust online.

The reputation heuristic signals a reliance on the reputation or name recognition of the websites or sources of web-based information as a credibility cue, rather than close inspection of site content or source credentials. Many people trust, for instance, big companies, such as Amazon.com, $\mathrm{CNN}$, as they are familiar to everyone. Information users often base their credibility assessment of such an organization's website content on the company brand name or reputation. "The reputation heuristic is likely psychologically rooted in part on a simpler heuristic principle of favoring recognized alternatives over less familiar options as a strategy for making judgments with minimal cognitive effort" $[15$, p. 426]. Applying this principle to the context of online credibility judgments, when choosing between sources, people are likely to believe that the source, the name of which they recognize, is more credible compared to unfamiliar sources. The reputation heuristic may also be a subset of the "authority" heuristic in the credibility assessment. The website or the reputation of the source serves as a heuristic credibility cue allowing users to avoid more effortful and systematic processing of the content as they evaluate online information.

"The endorsement heuristic suggests that people are inclined to perceive information and sources as credible if others do so also, without much scrutiny of the site content or source itself" $[15$, p. 427). People automatically tend to trust sites and sources that were either recommended by their acquaintances or come from aggregated testimonials, reviews, or ratings. Trust derived from acquaintances is an endorsement heuristic that is perhaps underpinned by a common form of heuristic reasoning known as the "liking/agreement heuristic" Trust derived from aggregated information sources stems from the presumption that the website is credible if the site or its source receives a lot of positive feedback (for example "star ratings").

The consistency heuristic - One of the common strategies for validating information is checking different websites to make sure that the information is consistent. This consistency heuristic can be accomplished by cross-validation - as a 
strategy for information evaluation. In most information-seeking situations, although requiring more cognitive effort than other heuristic strategies, the consistency heuristics function as a relatively quick means of arriving at a credibility judgment in comparison to more laborious methods of determining each source's identity and credentials, considering issues of the source potential bias or agenda, and searching when the information was last updated. Information found online can be validated with additional online and offline sources. In the situations where information is highly consequential (e.g., a large financial transaction or health situation), individuals state they cross-validate for consistency offline to a greater extent. The sources of those offline verifications are typically reported as being trusted acquaintances such as family and friends.

The self-confirmation heuristic - People tend to view information as credible if it confirms their preexisting beliefs and not credible if it negates their existing beliefs, regardless of how well-argued, duly researched, appropriately sourced, and so on, it is. With regard to processing online information (where lack of time and motivation often restrict users' ability to evaluate all information retrieved in a typical search) one can find confirmation that people tend to evaluate attitudinally-consistent information more favorably than inconsistent information [18]. In line with this principle, there is evidence that people tend to avoid information contradicting their existing beliefs, or, in other words, they employ selective filters to assist them in determining the credibility of information they find online - for example, by terminating searches when they find information that confirms their beliefs [15]. The self-confirming heuristic most probably stems from the false consensus effect researchers in cognitive psychology find that people tend not only to believe their own opinions to be right but also to be widely shared by others [19]. Such cognitive biases serve as ego defense mechanisms, resulting in a tendency for people to evaluate ambiguous information in a way that is beneficial to their own needs or interests.

The expectancy violation heuristic - Several types of expectancy violations that have implications for credibility were observed in the research of Metzger, Flanagin and Medders [15]. People often rely on the surface characteristics of websites and sources when evaluating their credibility. Site presentation features, website appearance, layout, and functionality are most the prevalent forms of expectancy violation. If a website fails to meet users' expectations in some way, they will immediately judge it as not credible. Bad grammar and typographical errors ("amateurish" sites) are a quick and easy way to determine the site credibility without a great deal of cognitive effort and scrutiny of message arguments, source qualifications and other more involved methods of information evaluation. Information users very often do not like websites asking for more information than necessary or providing more information than requested. They do not trust sites that give them something they did not ask for or expect to receive, for instance, being redirected to another site. Many participants of Metzger, Flanagin and Medders' [15] research expressed a tendency to view information as credible if it confirmed their pre-existing beliefs and not credible if it did not. The extent to which people feel that information confirms their own opinions or biases determines their perceived credibility of that information. The overarching logic is that people expect credible 
sources to present information in a clear and professional manner as a reflection of their expertise and attention to detail.

The expectancy-violation heuristic is likely underpinned in part by the "effort heuristic" [20], which is the human tendency to value objects based on how much effort was spent on their production.

Persuasive intent heuristic - The persuasive intent heuristic is a tendency to feel that information that may be biased is not credible. Internet users generally feel negative about the credibility of websites that present unexpected commercial content, intrusive advertising such as pop-ups or page-redirects. Many of them recognize it as a kind of red flag, perceiving it as some sort of manipulation, which elicits an immediate defense mechanism that leads people to mistrust information without further scrutiny. This phenomenon is discussed in terms of an intrusiveness heuristic, whereby unsolicited and unwelcome information negatively affects users' perception of website content because the annoyance generated by the information is projected on the site or source in question. In extreme situations, the suspicion of commercial intent led some users to stop using the entire top-level domain of .com websites as a source of credible information.

The list of the heuristics presented above is by no means exhaustive. Indeed, Sundar's MAIN model [7] suggests several other heuristics that may have an impact on credibility judgments, for example, "coolness" or "novelty" heuristics that could produce quick favorable credibility impressions of new websites or content, or the "prominence" heuristic that may lead to higher attribution of credibility to the sources that appear higher in search engine result pages prior to the inspection of the source or its content. All of this suggests that more research is needed to understand how people employ heuristics as they make judgments about credibility.

Many research results show that a common strategy employed by Internet information seekers is to minimize the cognitive effort and mitigate time pressures through the use of heuristics. It is possible to categorize the heuristics discussed into two general classes of credibility heuristics: one based on social confirmation, and the other one rooted in expectancies within the context. The idea of social confirmation seems to underpin the reputation, endorsement and consistency heuristics, all of them premised on the notion that credibility can be established from others' actions and beliefs. If a number of people use some websites or information, recommend it and agree with it, then information users assume it is credible. Although this heuristic works best in helping users find valid information, it is not perfect because it is subject to crowd behavior and may erroneously equate credibility with popularity [15, p. 435].

\section{Heuristics in the Context of Information Literacy}

Considering the concept of information literacy one should refer at least to three current discourses: "1) information literacy as the acquisition of "information age" skills, 2) information literacy as the cultivation of habits of mind, and 3) information literacy as engagement in information-rich social practices" [21]. 
The first definition of IL - very popular in library and information science - as a predefined set of information skills that should be achieved (still partly valuable to the educational and university context), does not befit the outside world, everyday information seeking, e-commerce and workplace practices. Pressed by lack of time and a growing number of information, media and sources, "ordinary" people use many mental shortcuts. From the point of view of the information professionals who emphasize the importance of organized processes of searching and evaluating information sources, heuristics can be perceived as unreliable tools leading to mistakes and errors.

Another interesting perspective is to consider heuristics in the light of habits of mind that facilitate information work, taking into account learning contexts, models of problem solving and cognitive approaches to the challenges of digital media. This perspective brings information literacy and information behavior in close alignment.

"IL as a social practice" is based on what works better rather than on what expert behavior or prescriptive models might show. "Rather than a list of discrete skills, information literacy is expressed in terms of general capabilities individuals have for living, learning, and working in an information-rich society" [21]. That means that IL is an evolving construct that encompasses the constantly changing nature of technology and the evolving expectations of people in their information and media environments. "This perspective sees participation as the key to developing information literacy" [21]. Research analysis of IL practice in digital environments, using social networking tools, confirms the high effectiveness of cognitive heuristics. The bandwagon heuristic rooted in social confirmation is one of the basic achievements in networked societies.

To sum up, the analysis of cognitive heuristics use by online information users offers some additional explanation of online information behavior and personal information management strategies - issues that are inextricably linked to information literacy. A literate person is not an isolated person, who individually acquires and uses his/her information (media) skills. Understanding the heuristic processes used in information seeking and evaluation (e.g. increasing individuals' reliance on more social means of online information processing and evaluation) should enable literacy educators and others to design better IL suggestions to increase the Internet users' information literacy and help them to assess the tangled Web while avoiding deception, manipulation, misinformation, information stress, unnecessary effort and waste of time. The result of the research is a proposal to treat heuristics as intuitive but not entirely accidental search tactics based on experience that should be included in the debate on information literacy.

\section{References}

1. Lloyd, A.: Information Literacy Landscapes: Information Literacy in Education, Workplace and Everyday Contexts. Chandos Publishing, Oxford (2010)

2. Špiranec, S., Kos, D.: Information Literacy Practices and Student Protests: Mapping Community Information Landscapes. Information Research, 18(3) paper C39 (2013) http://InformationR.net/ir/18-3/colis/paperc39.html 
3. Materska K.: Heuristics in the Untamed Information World. In: Nauka o Informacji w Okresie Zmian. Koncepcje, Metody, Badania, Praktyki. Ed. B.Sosińska-Kalata. Warszawa, Wydaw. SBP, p. 53-64 (Miscellanea Informatologica Varsoviensia vol. 7) in print

4. Metzger, M.J., Flanagin, A.J.: Credibility and Trust of Information in Online Environments: The Use of Cognitive Heuristics. Journal of Pragmatics 59, 210--220 (2013)

5. Metzger, M.J.: Making Sense of Credibility on the Web: Models for Evaluating Online Information and Recommendations for Future Research. Journal of the American Society for Information Science and Technology 58(13), 2078--2091(2007)

6. Hilligoss, B., Rieh, S.Y.: Developing a Unifying Framework of Credibility Assessment: Construct, Heuristics, and Interaction in Context. Information Processing \& Management 44(4), 1467--1484 (2008)

7. Sundar, S.: The MAIN Model: A Heuristic Approach to Understanding Technology Effects on Credibility. In: Metzger, M., Flanagin, A. (eds.), Digital Media, Youth, and Credibility, pp. 73--100. MIT Press, Cambridge, MA (2008)

8. Simon, H.A.: A Behavioral Model of Rational Choice. The Quarterly Journal of Economics 69(1), 99--118 (1955)

9. Huvila, I.: In Web Search We Trust? Articulation of the Cognitive Authorities of Web Searching. Information Research, 18(1) paper 567 (2013), http://InformationR.net/ir/18-1/paper567.html

10. Gigerenzer, G., Todd, P.M.: Simple Heuristics That Make Us Smart. Oxford University Press, New York (1999)

11. Gigerenzer, G., Gaissmaier W.: Heuristic Decision Making. The Annual Review of Psychology 62, 451--82 (2011)

12. Gigerenzer, G, Brighton H.: Homo Heuristicus: Why Biased Minds Make Better Inferences. Topics in Cognitive Science 1, 107--143 (2009)

13. Gigerenzer G.: Why Heuristics Work. Perspectives on Psychological Science 3(1), 20--29 (2008)

14. Tversky, A., Kahneman, D.: Judgment Under Uncertainty: Heuristics and Biases. Science 185, 1124--1131 (1974)

15. Metzger, M.J., Flanagin, A.J., Medders, R.: Social and Heuristic Approaches to Credibility Evaluation Online. Journal of Communication 60(3), 413--439 (2010)

16. Sundar, S.S., Xu, Q., Oeldorf-Hirsch, A.: How Deeply do We Process Online Recommendations? Heuristic vs. Systematic Processing of Authority and Bandwagon Cues. 63rd Annual Conference of the International Communication Association London, UK, June 17-21, 2013 (2013)

17. Sundar, S.S., Knobloch-Westerwick S., Hastall M.R.: News Cues: Information Scent and Cognitive Heuristics. Journal of the American Society for Information Science and Technology 58(3), 366--378 (2007)

18. Fischer, P., Jonas, E., Frey, D., Schulz-Hardt, S.: Selective Exposure to Information: The Impact of Information Limits. European Journal of Social Psychology 35, 469--492 (2005)

19. Ross, L., Greene, D., House, P.: The False Consensus Effect: An Egocentric Bias in Social Perception and Attribution Processes. Journal of Experimental Social Psychology 13, 279-$301(1977)$

20. Kruger, J., Wirtz, D., Van Boven, L., Altermatt, T.W.: The Effort Heuristic. Journal of Experimental Social Psychology 40(1), 91--98 (2004)

21. Addison, C., Meyers, E.: Perspectives on Information Literacy: A Framework for Conceptual Understanding. Information Research 18(3) paper C27 (2013), http://InformationR.net/ir/18-3/colis/paperc27.html 